\title{
THE ASSEMBLY PROCESS STABILITY ASSESSMENT BASED ON THE STRENGTH PARAMETERS STATISTICAL CONTROL OF COMPLEX METAL PRODUCTS
}

\author{
${ }^{1}$ Dorota KLIMECKA-TATAR, ${ }^{2}$ Renata DWORNICKA \\ ${ }^{1}$ Czestochowa University of Technology, Czestochowa, Poland, EU, dorota.klimecka-tatar@wz.pcz.pl \\ ${ }^{2}$ Cracow University of Technology, Poland, EU, renata.dwornicka@mech.pk.edu.pl \\ https://doi.org/10.37904/metal.2019.870
}

\begin{abstract}
In the paper, the results of statistical control of complex metal products have been presented. The statistical process control (SPC) is indicated as a solution developed to collect and analyse data, which allow to process performance monitoring. The process has been validated based on the evaluation of the process repeatability - repeatability in terms of meeting the criteria approving the product as compatible. As the basis for assessing the stability of the assembly processes the measurements of tensile strength (statistical tensile test) of metal hitch shaped by cold forming have been indicated. A set of the strength tests from 5 production days (in period 1 and 2) has been presented. The changes on histograms and frame-mustache charts have been highlighted as a first sign of deregulation of the forming machine - a threat to process stability in terms of efficiency and quality.
\end{abstract}

Keywords: Statistic control, SPC, control chart, assembly process, metal forming, tensile strength

\section{INTRODUCTION}

Companies in the metal industry, in order to maintain its competitive position in the market attach very great emphasis on the implementation of the most common techniques of production management. No matter for the company's strategy and the type of processes (service, production, processing or assembly processes), they require stability and predictable flow. One of the methods that will ensure stability and consistency of production is SPC (Statistical Process Control). SPC is a statistical method of monitoring and predicting the stability of the production process and, as a consequence, it makes it possible to interrupt the flow of processes when statistical indicators go beyond the limits of predictability and the result of the process are products with a high inconsistency index [1-4]. In many scientific works the significance of SPC with respect to Lean production techniques, management in accordance with TPM principles or TQM is underlined, analysed and analysed [5-8]. Basic and necessary tool in the SPC are control cards - Shewhart charts that allow concurrent with the process monitor their flow. Control cards are irreplaceable in the objective differentiation of the natural variability of process parameters criteria from unforeseen or unconventional events - objective differentiation based on the statistical parameters [9]. Control charts allow the process to be monitored in relation to the accepted products' eligibility parameters and if there are significant changes in the volatility or average value, it creates the possibility of process adjustment. SPC and the use of control cards is therefore one of the elements supporting the implementation of Lean Production, because it creates great opportunities to eliminate waste as well as improve the quality and efficiency of the process $[5,10]$. The published in international journal results show that there is a positive relationship between SPC and business performance $[1,3,5,6]$.

Statistical control of the process is particularly important from the point of view of serial production, which should be characterized by high efficiency while efficiency is consist of the availability of technical equipment, the quality of manufactured products and the ability of transformation. Statistical parameters of the process, and in particular their sudden and unpredictable changes are also the basis for improving machine maintenance $[8,11-14]$

The main purpose of this paper is to present and highlight the importance of a comprehensive approach to process analysis, in relation to assembly processes in the automotive industry. 


\section{EXPERIMENTAL}

Statistical and quality tests have been carried out on the basis of the metal hitches forming process. The purpose of this treatment is the assembly of two components: steel cable and the catch made of aluminium alloy. The assembly of finished products is carried out on an automatic hydraulic press, using cold forming, and as a resut the steel cable is fixed by compressive forces in the catch. In the discussed process as a basic parameter, subjected to statistical control of the process, the strength of the hitch has been designated. The strength parameters have been determined based on the static tensile test for the finished product. The results obtained from the statistical tensile test of the hitch (cables with catch) have been introduced to the sheet of control charts. Statistical analysis has been carried out for two research periods. The first research period (period 1) covered 5 working days, directly after the maintenance of the die in a hydraulic press used to shape the cable connection with the catch. The second research period (period 2) covered 5 working days in the middle of the die life cycle.

\section{RESULTS AND DISCUSSION}

Statistical control of the process has based on control charts in accordance to the tensile strength measurements. The process stability has been evaluated and the possible deregulations were searched. The observation of change trends had allowed corrective action to be taken, thus preventing the controlled parameter from exiting certain limits. Two sets of tensile strength measurements have been analysed (period 1 and period 2) of cardinality $n=125$ (each period). Based on the data sets, basic statistical measures have been calculated - the results are presented in Table 1.

Table 1 Statistical measures for the analysis of a data set regarding results from a statistical tensile test for finished hitches [own study]

\begin{tabular}{|l|c|c|c|c|c|c|}
\hline \multirow{2}{*}{ Variable } & \multicolumn{7}{|c|}{ Descriptive statistics } \\
\cline { 2 - 7 } & Mean & Median & Mode & Min & Max & Range \\
\hline Period 1 & 29.81 & 30.0 & 30.1 & 27.2 & 31.4 & 4.2 \\
\hline Period 2 & 28.69 & 28.9 & 30.5 & 24.1 & 32.2 & 8.1 \\
\hline & $\begin{array}{c}\text { Lower } \\
\text { quartile }\end{array}$ & $\begin{array}{c}\text { Upper } \\
\text { quartile }\end{array}$ & $\begin{array}{c}\text { Standard } \\
\text { deviation }\end{array}$ & $\begin{array}{c}\text { Coefficient } \\
\text { of variation }\end{array}$ & Skewness & Kurtosis \\
\hline Period 1 & 28.8 & 30.6 & 1.101 & 3.695 & -0.544 & -0.551 \\
\hline Period 2 & 26.5 & 30.8 & 2.421 & 8.439 & -0.317 & -1.178 \\
\hline
\end{tabular}

Multiple histograms have been used to present the distribution of the size of the studied variable in two periods (1 and 2) (Figure 1). The values of the tested variable in the analysed periods have been plotted against one $\mathrm{X}$ axis, which facilitated the comparison (Figure 2). For period 2, there is clearly a larger spread of test variable around the average value. Compared to period 1, the mean value of the parameter (for period 2) decreased. The mean value of the parameter has value $29.81 \mathrm{MPa}$ and $28.69 \mathrm{MPa}$ for period 1 and 2 respectively.

In period 1, the lowest recorded value is $27.2 \mathrm{MPa}(\mathrm{min})$, while the largest one is 31.4 (max), hence the range of results is 4.2 . While for the period 2 the smallest recorded value is $24.1 \mathrm{MPa}(\mathrm{min})$, the largest one is 32.2 $\mathrm{MPa}(\max )$, therefore the range is almost twice as large and is about $8.1 \mathrm{MPa}$. Most important, during period 2 a significant part of the measurements exceeded the permissible minimum value of hitch strength. For values lower than $27 \mathrm{MPa}$ the product is considered as not compliant with technical and safety requirements. For period 1 , the variability of the collected results is at $3.695 \%$ (coefficient of variation), which means the average variation, while, for period 2 , this coefficient has a value of $8.439 \%$, which already indicates a very large and unpredictable differentiation of results. 


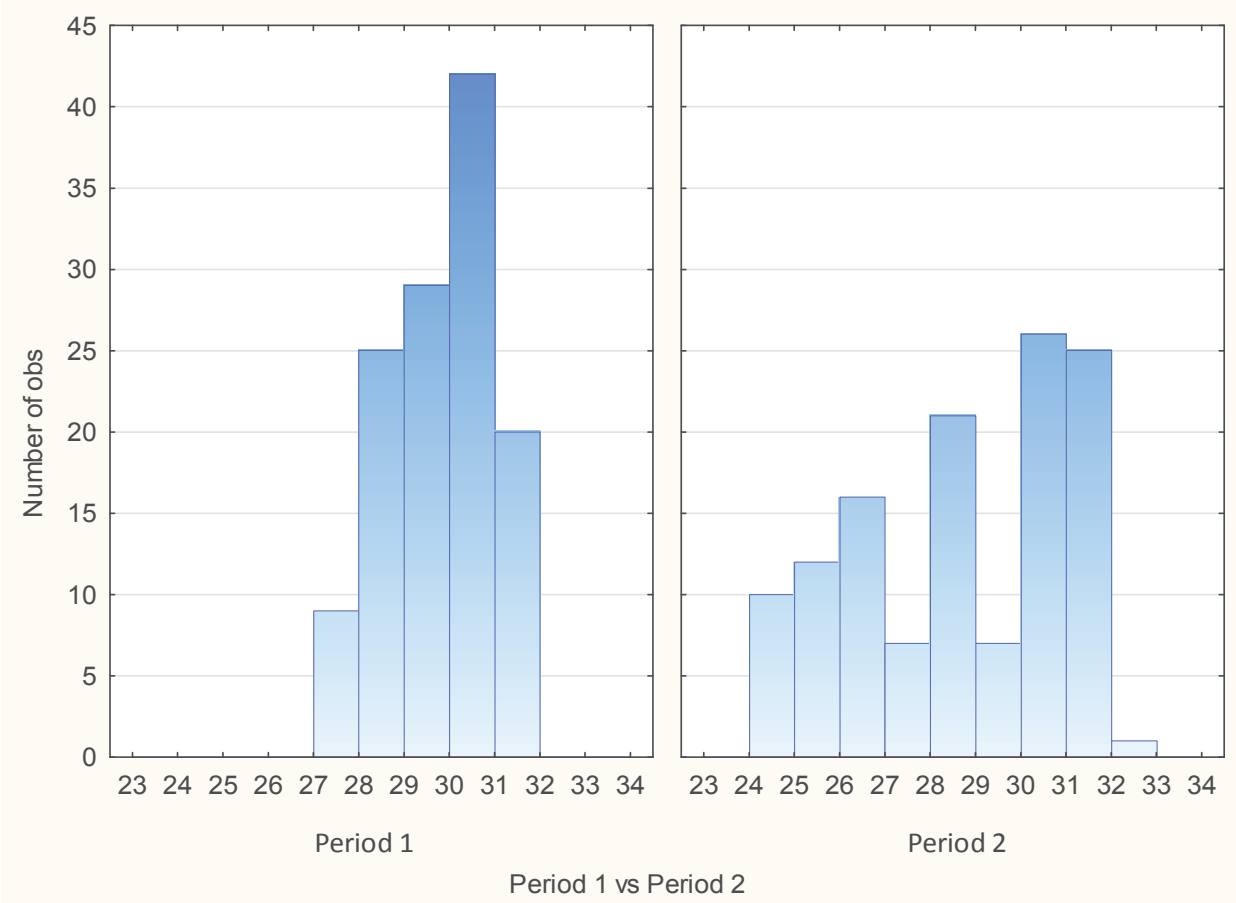

Figure 1 Histogram of the statistical tensile test results - period 1 and period 2 [own study]

The comparisons have been made on the basis of the tensile strength measurements histograms (Figure 2) and the frame-mustache graph (Figure 3).

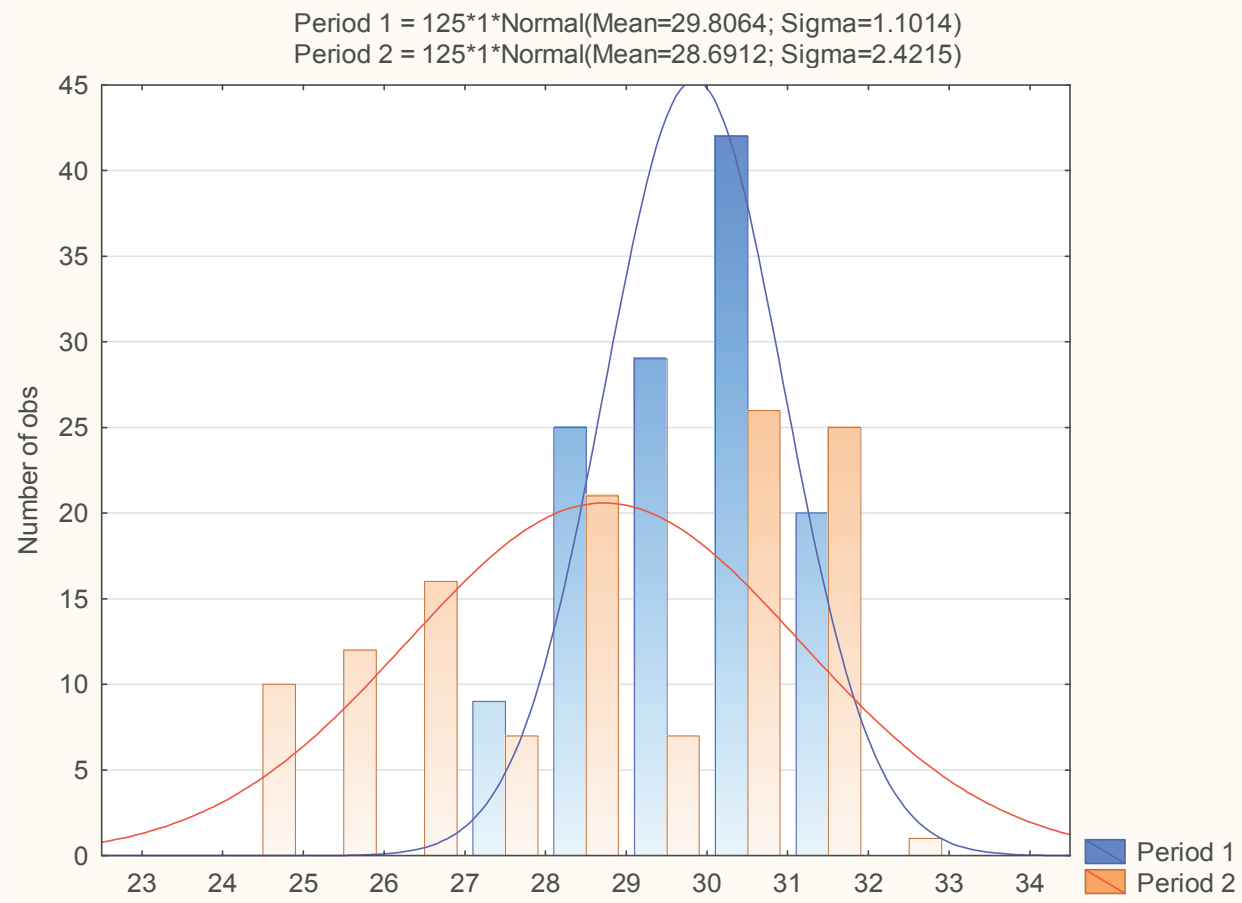

Figure 2 Comparison of statistical analysis of the process according to tensile test results - period 1 and period 2 [own study] 


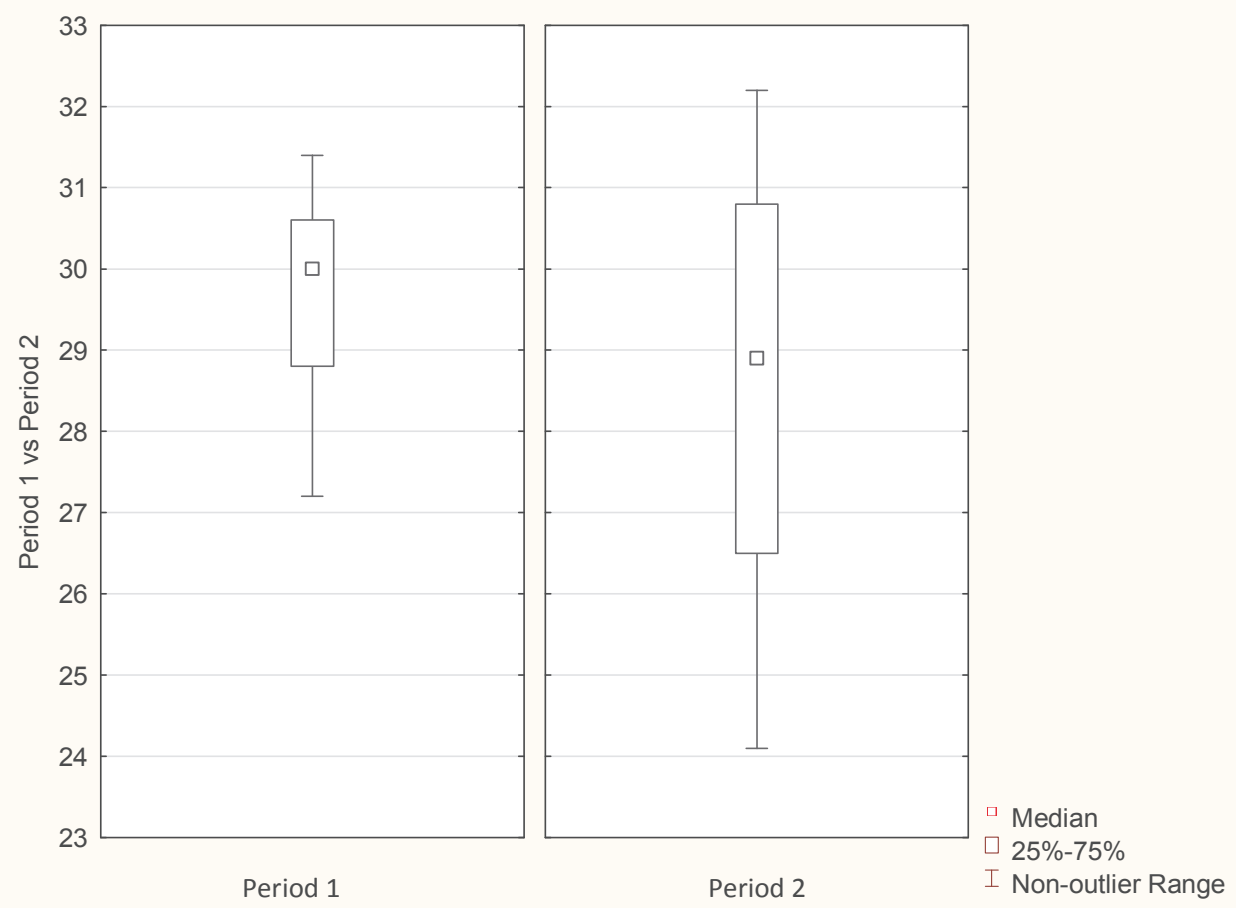

Figure $3 \mathrm{~A}$ frame-mustache chart for the analysis of the distribution of measurement values - period 1 and period 2 [own study]

On the basis of statistical control of the process, which main parameters were: assessment of the centering (position measurement) and spread (distribution of product features), it can be clearly stated that the process in period 1 is predictable in the course, whereas during the period 2 has significantly deregulated. The distribution of the test feature is clearly left-sided asymmetric. This is confirmed by the value of the skewness coefficient (skewness) much lower than 0 . On the other hand, the negative value of the coefficient of concentration (kurtosis) determines that the analysed distribution is clearly less slender than in the case of a normal distribution.

A small shift and significant dispersion of the measurement results for the second research period points to deregulation of the process. To complete the analysis of process and the manufactured products quality improvement all products after special control tests have to pass the visual analysis. Observations have been made, in particular, on products that went beyond the scope of the product's eligibility. This approach has given the ability to identify the most common causes of the strength properties deterioration, and therefore three main causes were identified:

- unstable connection of steel cable with an aluminium catch (cable protruding from the catch),

- $\quad$ breaking the steel cable,

- deformation or cracking of the aluminium catch.

As can be seen from the technical documentation and the conducted FMEA analysis, such damages are events with the highest risk of emergence. According to technical data, correctly made and formed metal catch should be damaged by plastic deformation of the aluminium catch and have to be characterized with minimal strength of $27 \mathrm{MPa}$. Removing the cable from the catch as the reason for the destruction of the element occurred relatively frequently (over $80 \%$ ). The catch of this type of elements are made of aluminium alloy (susceptible to cold forming), delivered in the form of forgings with a crimping tip on a steel cable. A suitable compression (by cold forming using a die that has been subjected to efficiency analysis) is intended to suitably fit the steel cable and thus create a durable connection. The technical assumptions of the product indicate that 
the durability of the formed joint should not negatively affect the strength of the product. Damage can be expected in the area of the cable and the area of the aluminium catch itself.

Changes in the values of the statistical parameters are the first signal informing about the upcoming maintenance of the machine. Interestingly, according to information obtained in the course of production, in accordance with the assumptions of TPM procedures functioning on the above-mentioned production line, the second period of production corresponded only to half of the die's life. Therefore, it can be concluded that the main reason for the process disruption and the reduction of its predictability is the excessive wear of the forming die. Consequently, it can be assumed that further production on this technical equipment is subject to a very high risk of non-compliance. In the case of such series production, this is the first alert to modify the maintenance periods of the device. Ensuring a high level of availability of technical equipment can significantly contribute to improving the quality of products obtained in the cold forming process. This is particularly important from the point of view of the application of manufactured elements (automotive industry) and from the point of view of the main principles of Lean production - minimizing losses, reducing waste (mud) in the whole production process. Statistical analysis carried out in this way proves that exploitation of the die (even slight destruction of the die) has a significant impact on the final product, and in particular on the quality of the entire production series.

Among the further remedial and corrective actions, there should appear an additional action in the area of the die design. Modification of the die should be based on possible replacement of material from which it was made, as well as possible dimensional modifications. What should be noted as a consequence, it is also possible that the pressing force of dies should be subjected to further analysis.

\section{CONCLUSIONS}

On the basis of the statistical quality control results, can be concluded that the results of product characteristic parameters and statistical analysis of these parameters enable proper process control. Variability of statistical parameters in different research periods is the basic information to introduce remedial actions in the field of process improvement. In the discussed example, on the basis of the first observations, it has been stated that, the areas for corrective actions were mistaken - improvement was sought in replacing the material with the catch. While a comprehensive analysis made it possible to conclude that the main reason for the occurrence of non-compliance is the excessive use of technical equipment. The exploitation of the die has a significant impact on the final product, and in particular on the quality of the entire production series. Presented methods and obtained results may be useful in similar situation e.g. material science analyses [15, 16], a thermal load of a device [17] or an industrial quality management [18].

\section{REFERENCE}

[1] COSTANTINO, F., DI GRAVIO, G., SHABAN, A., and TRONCI, M. A real-time SPC inventory replenishment system to improve supply chain performances. Expert Systems with Applications. 2015. vol. 42, pp. 1665-1683.

[2] SOUSA, S., RODRIGUES, N., and NUNES, E. Application of SPC and Quality Tools for Process Improvement. Procedia Manufacturing. 2017. vol. 11, pp.

[3] WU, Z., SHAMSUZZAMAN, M., WANG, Q., The cost minimization and manpower deployment to SPC in a multistage manufacturing system. International Journal of Production Economics. 2007. vol. 106, pp. 275-287.

[4] KOWALIK, K. Six sigma as a method of improving the quality of service process. Production Engineering Archives. 2018. vol. 19, pp. 10-15.

[5] AHMAD, M. F., ZAKUAN, N., JUSOH, A., and TAKALA, J. Relationship of TQM and Business Performance with Mediators of SPC, Lean Production and TPM. Procedia - Social and Behavioral Sciences. 2012. vol. 65, pp. 186191.

[6] RODRIGUES, M., and HATAKEYAMA, K. Analysis of the fall of TPM in companies. Journal of Materials Processing Technology. 2006. vol. 179, pp. 276-279. 
[7] SHEN, C.-C., Discussion on key successful factors of TPM in enterprises. Journal of Applied Research and Technology. 2015. vol. 13, pp. 425-427.

[8] MIELCZAREK, K. and KNOP, K. Assessment of production processes functioning in the case of air bag production. MATEC Web of Conferences 2018, 183, 04009, 2018, pp. 1-6.

[9] BRZEZIŃSKI, S. and KLIMECKA-TATAR, D. Effect of the changes in the forming metal parameters on the value streams flow and the overall equipment effectiveness coefficient. In METAL 2016: 25th Anniversary International Conference on Metallurgy and Materials, Ostrava, TANGER, 2016, pp. 1750-1755.

[10] INGALDI, M. and DZIUBA, S.T. Modernity Evaluation of the Machines Used During Production Process of Metal Products. In METAL 2015: 24th International Conference on Metallurgy and Materials. Ostrava. TANGER, 2015, pp. 1908-1914.

[11] NAEBULHARAM, R., and ZHANG, L. Performance Analysis of Serial Production Lines with Deteriorating Product Quality. IFAC Proceedings Volumes. 2013. vol. 46, pp. 501-506.

[12] ZHANG, Y., and YANG, M. A coordinate SPC model for assuring designated fit quality via quality-oriented statistical tolerancing. Computers \& Industrial Engineering. 2009. vol. 57, pp. 73-79.

[13] PEYMANKAR, M., DEHGHANIAN, F., GHIAMI, Y., and ABOLBASHARI, M. H. The effects of contractual agreements on the economic production quantity model with machine breakdown. International Journal of Production Economics. 2018. vol. 201, pp. 203-215.

[14] STYLIDIS, K., WICKMAN, C., and SÖDERBERG, R. Defining Perceived Quality in the Automotive Industry: An Engineering Approach. Procedia CIRP. 2015. vol. 36, pp. 165-170..

[15] BARA, M., KMITA, T. and KORZEKWA, J. Microstructure and properties of composite coatings obtained on aluminium alloys. Arch. Metall. Mater. 2016. vol. 61, pp. 1107-1112.

[16] GADEK-MOSZCZAK, A., RADEK, N., WRONSKI, S. and TARASIUK, J. Application the 3D image analysis techniques for assessment the quality of material surface layer before and after laser treatment. Adv. Mat. Res. Switz. 2014. vol. 874, pp. 133-138.

[17] OPYDO, M., KOBYLECKI, R., DUDEK, A. and BIS, Z. The effect of biomass co-combustion in a CFB boiler on solids accumulation on surfaces of P91 steel tube samples. Biomass \& Bioenergy.2016. vol. 85, pp.61-68.

[18] INGALDI, M. and DZIUBA S.T. Modernity evaluation of the machines used during production process of metal products. In METAL 2015: 24th Int. Conf. on Metallurgy and Materials. Ostrava: TANGER 2015, pp. 1908-1914.

[19] DZIUBA, S.T., INGALDI, M. and KADLUBEK, M. Use of quality management tools for evaluation of the products' quality in global economy. In 16th Int. Scientific Conf. on Globalization and its Socio-Economic Consequences. Žilina: Univ.of Zilina, 2016, pp. 425-432. 